\title{
Examen de las formas en Facsímil, de Alejandro Zambra
}

\section{Q Alexandra Saavedra Galindo \\ Investigadora posdoctoral del Centro de Investigaciones sobre América Latina y el Caribe de la UNAM, México}

Recibido: 10/8/2017. Aprobado: 8/12/2017.

\begin{abstract}
Resumen
En este trabajo ${ }^{1}$ se estudia la forma en que la obra de Alejandro Zambra (1975) se construye atendiendo a un proyecto de arte literario no convencional. La reflexión se centra en el análisis de Facsímil (2015), obra en la que el escritor chileno toma como hipotexto el formato de la Prueba de Aptitud Académica a la que se sometía en Chile a los estudiantes que se postulaban para ingresar a la Universidad. La obra narrada por medio de la estructura de la prueba permite reflexionar no solo sobre estrategias de creación literaria poco comunes, sino sobre la figura de autoridad del escritor que se mina con las formas excepcionales del relato. Esta obra recoge y reconstruye fragmentos que pueden leerse como minificciones, poemas, cuentos o, de manera global, como textos novelísticos. No obstante, aunque los argumentos de Facsímil pueden seguirse sin dificultad, es importante tomar en consideración que la forma de elaboración elegida por el autor no es gratuita y responde a un interés particular en que el concepto del libro sobresale por encima del contenido de la obra. Esta investigación toma en cuenta los diversos contextos de significación literarios, culturales y sociales con los cuales dialoga la obra Zambra.
\end{abstract}

\section{Examination of the forms in Facsimil de Alejandro Zambra}

Palabras clave

Géneros literarios Autor-Lector Evaluación Educación Literatura chilena

1. Este trabajo hace parte de la investigación posdoctoral «Ruptura genérica en la literatura latinoamericana contemporánea (siglo xxi)", que se realiza con el apoyo del Programa de Becas Posdoctorales de la Coordinación de Humanidades de UNAM, en el Centro de Investigaciones sobre América Latina y el Caribe.

\section{Keywords}

Literary genres Author-Reader Evaluation

Education

Chilean literature 
Palavras-chave

Géneros literários Autor-Leitor Avaliação Educação literatura chilena
However, although the plot of Facsimil can be followed without difficulty, it is important to take into consideration that the form has not been chosen at random and it is neither a whim and responds to a particular interest in which the concept of the book stands out above the content of the work. This research takes into account the diverse contexts of literary, cultural and social significance with which the Zambra work dialogues.

\section{Resumo}

No presente trabalho estuda-se a forma em que a obra de Alejandro Zambra (1975) se constrói atendiendo a um projeto de arte literário não convencional. A reflexão centrase na análise de Facsímil (2015), obra em que o escritor chileno toma como hipotexto o formato da Prova de Aptidão Acadêmica, a qual deviam realizar os estudantes para postularem para ingresar na Universidade no Chile. A obra narrada por meio da estrutura da prova permite refletir não somente sobre as estratégias de criação literária pouco comuns, mas também acerca da figura de autoridade do escritor que se mina com as formas excepcionais do relato. Esta obra recolhe e reconstrói fragmentos que podem ser lidos como minificções, poemas, contos ou, de forma global, como textos novelísticos. Não obstante, embora os argumentos de Facsímil possam ser seguidos sem dificuldade, é importante ter em consideração que a forma de elaboração elegida pelo autor não é gratuita e responde a um interesse particular em que o conceito do livro sobresai por cima do conteúdo da obra. Esta investigação tem em conta os diversos contextos de significação literários, culturais e sociais com os quais dialoga a obra Zambra.

Una de las actitudes que suele presentarse en casi todas las reseñas y críticas que, hasta la fecha, se han escrito sobre Facsímil (2014), del escritor chileno Alejandro Zambra, es la preocupación sobre cómo enfrentarse con ese tipo de texto. Desconcertados ante el formato que presenta la obra y los diversos elementos paratextuales, tales como la hoja de respuesta y el subtítulo, «Libro de ejercicios», con los que se anuncian los rasgos que distancian este libro de escritos narrativos que siguen formas genéricas tradicionales, no es extraño que tanto el lector como la crítica se pregunten qué clase de obra es exactamente Facsímil. De forma que la pregunta previa es ya un cuestionamiento por el sentido; al mismo tiempo que lo es por el contenido, si se quiere. Es decir, reflexionar sobre qué es Facsímil es hacerlo sobre el terreno en el que esta se halla formalmente, porque la forma es también, en este tipo de literatura, de narrativa, parte del contenido. No es asunto menor que el formato elegido sea el que es, pues este se recibe desdoblado en su sentido y en su significación. Por una parte, cuestiona los modos narrativos tradicionales, al desvelar el carácter hegemónico de estos, al servicio de intereses no estrictamente artísticos o, por el contrario, artísticos, sometidos a un código de significaciones conocido de antemano y sancionado por un orden cultural y social concreto. Pero, en segundo lugar, dirige la atención del lector hacia esas zonas de la experiencia que no suelen presentarse bajo su formalización literaria o artística. Quizá, no pueda entenderse bien el sentido de la obra si esta no se describiera en primer lugar formalmente, antes de abandonarse el lector a su significado o al mismo tiempo que se considera este. En qué consiste Facsímil, cuál es su morfología, sus partes constituyentes, su articulación interna. Estas son las preguntas previas.

Como ya se ha mencionado, lo primero que llama la atención de esta obra es el formato que ha elegido Zambra para desarrollarla. Un formato que, según declaraciones del autor (Soto, 2014), corresponde al esquema y estructura de la Prueba de Aptitud Académica que fue aplicada a los estudiantes chilenos en 1993. La prueba se conocía por sus siglas: PAA, un modelo de examen que se utilizó durante treinta y cinco años, 
entre 1967 y hasta 2002, para evaluar a los estudiantes que aspiraban a ingresar a la educación universitaria ${ }^{2}$. El puntaje obtenido tras haberse sometido a la prueba determinaba, en gran medida, cuál sería el destino académico de los jóvenes, ya que con aquella se establecía no solo si el postulante era apto para ingresar al sistema universitario, sino a qué tipo de carrera académica, de estudios, podía optar. Creada por la Universidad de Chile, esta prueba se popularizó y sirvió como herramienta uniforme para que el resto de las universidades contara con un proceso análogo de admisión a sus estudios; sin embargo, cada institución académica tenía potestad para definir los puntajes mínimos de ingreso, así como para establecer puntajes específicos para carreras de alta demanda.

La PAA estaba compuesta por tres secciones de carácter obligatorio que comprendían una prueba de Aptitud Verbal, una de Aptitud Matemática y la de Historia de Chile, añadida esta última en 1985, más otras pruebas de carácter específico (PCE), en las que se evaluaban los conocimientos sobre ciencias sociales, biología, química, matemática y física, de acuerdo a la(s) carrera(s) a las que optara el aspirante. Para aprobar la PAA, los estudiantes debían responder a un grupo de preguntas que contaban con cinco opciones de respuesta $(A, B, C, D, E)$, de las que solo una era considerada como correcta, y que debía ser marcada en el círculo correspondiente en unos cuadernillos especiales que se entregaban adjuntos a la PAA. Posteriormente, los cuadernillos eran leídos por un sensor foto-óptico que contaba el número total de aciertos. Una vez se conocían los resultados, los aspirantes debían entregar a la universidad una lista de doce carreras en las que deseaban ser admitidos. No obstante, la decisión final era tomada por el sistema de las universidades, que ponderaban los resultados de la PAA en función de los criterios establecidos en el sistema de admisiones de cada institución. A los estudiantes de los últimos cursos de educación media se les preparaba para la presentación de la PAA a través de la realización de ejercicios y exámenes similares. Para los estudiantes candidatos a ingresar en la universidad, como suele ser el caso con este tipo de pruebas, el estudio se convertía, en alguna medida, más en el conocimiento de la prueba misma que en el estudio de los contenidos de las materias concretas.

Todos estos datos de índole tanto histórica como formal resultan relevantes en Facsímil, dado que exponen el marco de referencia en el que se inserta la narración. Al mismo tiempo, los datos exhiben el interés del autor por elegir un formato que se rebela contra la incomodidad y limitaciones coercitivas de las convenciones empleadas en obras que se expresaban mediante los géneros literarios tradicionales. Zambra elige la PAA para expresar una serie de ideas sobre las que quiere que el lector reflexione y se cuestione, entre las ideas destaca el sistema educativo y de evaluación que se transparenta a través de la propia prueba; sin embargo, no deja claro el autor si esta obra debe ser leída como una novela, como una prueba o, incluso, como se arriesga a proponer G. Soto, como un texto transfronterizo que "huye de la poesía y del relato".

El libro, al igual que la prueba de Aptitud Verbal, está compuesto por cinco partes: Término excluido, Plan de redacción, Uso de Ilativos, Eliminación de oraciones y Comprensión de lectura. Las diferentes partes suman un total de noventa preguntas. Como se ha mencionado, al final del texto, hay una hoja de respuestas que le permite al lector marcar las que ha considerado "correctas"; no obstante, desde la primera pregunta se manifiesta el deseo que tiene el autor de polemizar sobre el referente del término "Facsímil", que en Chile se asocia con la PAA y con la medición estandarizada de conocimientos, así como sobre la preparación que se les daba a los estudiantes para enfrentarse con aquella. En ese sentido, "Facsímil" puede relacionarse o no con: “a) copia, b) imitación, c) simulacro, d) ensayo, e) trampa" (Zambra, 2014: 15). En realidad, entre los estudiantes chilenos que optaban al ingreso en la universidad, la voz facsímil no era la de la definición común para
2. En 2004 esta prueba fue sustituida por la Prueba de Selección Universitaria (PSU) o Sistema Único de Admisión, que cumple el mismo objetivo y que aún está vigente. 
el resto de los hispanohablantes, para los que, siguiendo la definición de la RAE, un facsímil es una: "perfecta imitación de una firma, de un escrito, de un dibujo, de un impreso, etc.' Esa definición había sido suplantada por algo que, ciertamente, no es un facsímil, en su sentido recto, sino por algo que es una prueba académica que puede recibir diferentes nombres. Del mismo modo, lo que se ofrece al lector no es una novela, sino algo que ha suplantado las formas tradicionales de la novela o de la poesía, un texto que se percibe como una obra literaria a través del proceso de manipulación mediante el que la prueba académica deja de ser una prueba académica y se convierte en una obra literaria.

Usar la PAA como formato y Facsímil como título, permite que el lector se relacione con un texto que problematiza el concepto de lo que puede considerarse o no como una obra literaria, mientras que el autor lo explora y experimenta durante y a lo largo de toda la escritura de esta. En relación con esta idea, es importante recordar las palabras de Ulises Carrión, quien consideraba que, tradicionalmente, se cree que un escritor no escribe libros, sino que escribe textos. El hecho de que los textos se encuentren dentro de un libro solo obedece a una decisión en torno a la dimensión y secuencia espacio-temporal que hace que se los incorpore a uno u otro formato literario (2016: 37-39). Pero Carrión plantea, justamente, que "en el arte nuevo el escritor hace libros" (39), lo que en Facsimil se traduce en la elección y decisión por parte del autor de tomar elementos formales ajenos a los que tradicionalmente son empleados en la narrativa, con el fin de subvertir la tradición que se cuestiona, de manera que en el proceso una prueba académica termine convirtiéndose en obra literaria.

La forma en la que se presenta el contenido de Facsímil intensifica la sensación de estar frente a un objeto literario que elude las restricciones genéricas. La primera sección, "TÉRMINO EXCLUÍDO", se ampara en las características del lenguaje poético:

22. Silencio
A) mutismo
B) afonía
C) sigilo
D) omisión
E) cobardía
23. Silencio
A) fidelidad
B) complicidad
C) valentía
D) lealtad
E) confianza

24. Silencio
A) silencio
B) silencio
C) silencio
D) silencio
E) silencio (Zambra, 2014: 19)

Las preguntas proponen un juego de solapamiento de las áreas semánticas, de los sinónimos y antónimos, a los que se agrega el ritmo monótono de lo que parece el silencio 
siempre presente, repetido cinco veces en la última secuencia de opciones. Todo ello trasciende el campo de la elección correcta o incorrecta de la respuesta y sitúa el presunto análisis léxico en el terreno de la responsabilidad estética o moral. La descripción puramente física se abandona en dos pasos, "1mutismo, afonía", para abordar en los ocho siguientes pasos, "2sigilo, omisión, cobardía, fidelidad, complicidad, valentía, lealtad, confianza", el universo de la responsabilidad ética; tómese como ejemplo el par antónimo valentía / cobardía, con la que en el fuero interno de cada uno se establece el sentido del silencio. Finalmente, así lo impone la prueba, no puede evitarse la respuesta única, el silencio lo domina todo y este puede definirse a través de una, de cualquiera, o de todas las posibles respuestas anteriores. La elección apropiada de los términos se lleva a cabo mediante una asociación poética que contamina el sentido de cada término particular.

Pero, a medida que avanza la obra, la poesía se transforma y da espacio a fragmentos de índole minificcional, como los que se incluyen en la sección II. Plan de redacción:

27. Un hijo

1. Sueñas que pierdes un hijo.

2. Despiertas.

3. Lloras.

4. Pierdes un hijo.

5. Lloras.
A) $1-2-4-3-5$
B) $1-2-3-5-4$
C) $2-3-4-5-1$
D) $3-4-5-1-2$
E) $4-5-3-1-2$ (Zambra, 2014: 23)

La minificción queda expresada en la prueba, en el examen, en su formulación abstracta, implícita en un texto que se construye mentalmente y que se sustituye por su notación aritmética. Cada uno de los elementos sustituidos encierra un relato diferente, sobre cada uno de ellos debe pronunciarse, antes de tomar la decisión definitiva, quien redacta el examen. Pero el examen se ejerce sobre una materia que primero debe tomar en cuenta el principio de realidad / irrealidad que incluye la oposición del par sueño / vigilia. Así como debe pronunciarse sobre la dramatización adecuada a lo expresado. Curiosamente, se le hurta al examinando una de las secuencias dramáticas más probables, la que se establece en la secuencia de la pregunta sobre la que se lleva a cabo la elección:

3 Sueñas que pierdes un hijo. Despiertas. Lloras. Pierdes un hijo. Lloras.

Y se le proporcionan al lector, al estudiante, otras alternativas que permiten organizar el texto como si se tratara de una combinación aleatoria de elementos.

4 Sueñas que pierdes un hijo. Despiertas. Pierdes un hijo. Lloras. Lloras. Sueñas que pierdes un hijo. Despiertas. Lloras. Lloras. Pierdes un hijo. Despiertas. Lloras. Pierdes un hijo. Lloras. Sueñas que pierdes un hijo. Lloras. Pierdes un hijo. Lloras. Sueñas que pierdes un hijo. Despiertas. Pierdes un hijo. Lloras. Lloras. Sueñas que pierdes un hijo. Despiertas.

Piénsese que la prueba de admisión a los estudios universitarios, que es el hipotexto de esta obra, estuvo en vigor, como se ha señalado, entre 1967 y hasta 2002, es decir, el período que apenas desborda en unos pocos años, hacia adelante y hacia atrás, el tiempo en que Chile estuvo gobernado por una dictadura encabezada 
por Augusto Pinochet. La pérdida de un hijo alcanza una elaboración dramática en ese contexto que se camufla en la experiencia de redactar y de responder una prueba de un examen. El acontecimiento, de un dramatismo difícilmente superable, queda disecado, anulado, vuelto inocuo, en una prueba en la que, inesperadamente, irrumpe la realidad a pesar del esfuerzo por reducirla a una notación numérica. La hondura de la tragedia, "Pierdes un hijo. Lloras. Lloras. Sueñas que pierdes un hijo. Despiertas", se ha suprimido al expresarla mediante una variante que la reduce a su abstracción aritmética: "4-5-3-1-2". Las emociones humanas se han evaporado en su representación numérica. La crítica, la que establece cómo esas emociones humanas desaparecen del horizonte de las inquietudes humanas, es multidireccional. Apunta a un estado social y a la literatura. Y lo hace de forma simultánea. Apunta hacia todos los mecanismos de sustitución que eluden enfrentarse con la tragedia y la disimulan, sea la sociedad, en su orden político y moral, sea la literatura que no desea mirar hacia algo que representa una manifestación única del dolor humano. El "Plan de redacción" consiste en no ver el posible orden natural de los acontecimientos. El "Plan de redacción" manipulado muestra la secuencia invisible que no se brinda como posibilidad para quien contesta las preguntas, y que se sirve de las emociones humanas y del dolor humano como una combinación más o menos aleatoria de elementos, una combinación en la que el dolor entra como un ingrediente aséptico más en un cálculo de probabilidades.

Las siguientes tres secciones crecen en extensión y le conceden a Zambra la posibilidad de hacer que el texto transite por discursos que pueden ser leídos como pequeños ensayos, como relatos, como nouvelle o, incluso, como fragmentos epistolares. Precisamente, el texto núm. 3 de la Sección II COMPRENSIÓN DE LECTURA, posee un tono epistolar que parece confirmarse en el apartado de las preguntas, específicamente en las 88 y 90 :

88. ¿Cuál sería, a tu juicio, la carpeta del correo más adecuada para un texto como éste?
A) Mensajes enviados.
B) Borradores.
C) Spam.
D) Mensajes no enviados [...]
90. Si fueras el destinatario de esta carta, tu reacción sería... (Zambra, 2015: 87)

Sin embargo, aunque las características del texto y las preguntas persuaden al lector para que piense que se trata de una carta electrónica, previamente, la segunda pregunta ha dejado abiertas otras dos posibilidades, la de los vínculos que el texto puede tener con una canción o con un poema de Enrique Lihn.

84. Un título más o menos bueno para el texto leído es:
A) My Generation (The Who).
B) Generación de mierda (Jorge González).
C) El perro mocho (Los Tigres del Norte).
D) Father $\mathcal{E}$ Son (la canción de Cat Stevens que en una parte dice «Look at me/I am old/ but I'm happy», pero no da la impresión de que ese padre sea feliz, de hecho ése es el momento más triste de toda la canción).
E) Monólogo del padre con su hijo de meses (Enrique Lihn, aunque del texto se desprende que el hijo tiene dieciocho años, es decir doscientos dieciséis meses). (Zambra, 2015: 85) 
Esta indefinición genérica dota a Facsímil de una flexibilidad que difícilmente poseen obras cuyas formas son más fijas. Cual si fuera un juego en el que los géneros se cuestionan al mismo tiempo que se mezclan, Facsímil permite que

\begin{abstract}
(...) una prueba académica se lea más allá de su formato y se vean en ella sus posibilidades como obra de arte. Siguiendo el tipo de procedimiento que popularizó Duchamp al tomar elementos cotidianos (un mingitorio, una pala, una rueda, un taburete o un vidrio) que se leen, interrogan y analizan alejados del contexto o usos para los que fueron diseñados, Zambra distancia la prueba académica del espacio de tensión que representa ser evaluado y del uso para la que fue concebida, y la ubica en el espacio literario, un lugar en el que lo estético es también un espacio abierto a la crítica, al debate y al análisis. El libro examen hace difícil que el lector tenga claridad sobre el género al que pertenece la obra y, por lo tanto, la forma de vincularse con ella. "La reflexión sobre los géneros literarios se vincula cada vez más con la reflexión sobre géneros no literarios" (Vital, 2012: 33) una tendencia que, según Alberto Vital, es cada vez más frecuente en la literatura y que Facsímil ejemplifica.
\end{abstract}

Facsimil se resiste a las etiquetas y a los límites, y es consecuente con el deseo del autor, para quien la descripción y definición de su libro debe eludirse. En ese sentido, el autor afirma que no desea decir que esta es una obra experimental.

(...) del mismo modo que no quise bautizarlo como una novela ni como poesía ni como nada. Los géneros literarios son camisas incómodas que te pones y un libro es la historia de esa incomodidad. Y la Prueba Verbal era como un género literario, quizás el primero cuyos mecanismos comprendí. (Careaga, 2014: 2)

El formato de la PAA, en el que el lector se ve confrontado por las preguntas explícitas de la prueba, pone de manifiesto la forma en la que las obras de arte también sirven, entre otras cosas, para cuestionar, desestabilizar o plantear reflexiones sobre ideas, costumbres, tradiciones, sobre la vida cotidiana, la familia, la educación, la sociedad, la política y el propio arte. Las preguntas y su posibilidad de hallar una respuesta dentro de las opciones que se enlistan, hacen de Facsímil un libro que, volviendo a Carrión, formula diferentes posibilidades de lectura y crea condiciones específicas para ella (2016: 59-60). Zambra involucra al lector en un proyecto en el que cada lectura, cada elección, transforma la obra, su historia y lo que esta representa. Desde luego, el papel activo que debe tomar el lector no pretende presentarse como una novedad; más bien, funciona como una herramienta que hace que este se acerque al texto de una forma diferente a como lo haría en el caso de una obra literaria tradicional. El lector puede leer la obra de manera convencional o puede hacerlo involucrándose, eligiendo, organizando su contenido. Cualquier decisión que se tome sobre la lectura es igualmente oportuna. Justamente, una de las intenciones que Zambra tenía con este libro puede suponerse que era la de poner de manifiesto que ni en los exámenes ni en la vida hay respuestas completamente correctas o incorrectas, respuestas únicas. Más aún, el lector es continuamente interpelado por el sentido, la oportunidad, la necesidad o las intenciones de las preguntas. Las respuestas apuntan todas ellas al cuestionamiento de las preguntas. Tanto las que aparecen como, así se entiende, las que no aparecen en la prueba y a las que al redactor, al lector, le gustaría contestar, le gustaría que se formularan. El examen no es un documento vacío, racional, ajeno a los sentimientos humanos, clínico, imparcial, sino que está lleno de significación sobre la pretendida neutralidad de la razón.

La prueba, además, consiente la identificación y la empatía al ser un mecanismo que apela a que el lector recuerde aquellas oportunidades en las que ha debido resolver un cuestionario con características similares. Y, aunque en principio los editores tenían dudas sobre cómo funcionaría una obra de estas características fuera de Chile, los 
lectores de otros países han sabido hallar el equivalente correspondiente. Las pruebas de selectividad en España o el examen de ICFES en Colombia, son dos ejemplos de ello. Pero que existan esas posibilidades de hacer equiparables las experiencias de evaluación por medio de un mismo sistema intensifica y hace global la incomodidad ante un formato estandarizado, restrictivo y esquemático, que, supuestamente, sirve para medir las competencias y aptitudes de las personas, pero que, en el fondo, hace abstracción de esa misma humanidad a la que se dirige. Esa prueba oficial, no la manipulada por Alejandro Zambra, se sitúa en un plano de racionalidad que la vuelve posthumana.

Fácsímil expone y discute los métodos estandarizados de evaluar los conocimientos. Al usar la PAA, así como al narrar las experiencias de un grupo de jóvenes que se preparan para presentarla, en el texto núm. 1, del apartado V. Comprensión de lectura, Zambra hace explícita su crítica sobre un sistema educativo y de evaluación en el que no se promueve el pensamiento crítico, la argumentación ni las habilidades para expresar y defender las ideas propias. Para el autor, el sistema educativo está diseñado para disuadir y adoctrinar, antes que para entusiasmar. En ese sentido, es importante recordar que la preocupación por este tema ya había tenido espacio en otras obras del autor chileno. En Formas de volver a casa (2011), por ejemplo, el narrador hace la siguiente afirmación:

No gastaban saliva hablando sobre el placer de la lectura, tal vez porque ellos habían perdido ese placer o nunca lo habían sentido realmente. Se supone que eran buenos profesores, pero entonces ser bueno era poco más que saberse los manuales.

Al tiempo ya conocíamos los trucos, transmitidos de generación en generación. Se
nos enseñaba a ser tramposos y aprendíamos rápido. En todas las pruebas había un
ítem de identificación de los personajes, que incluía puros personajes secundarios:
mientras menos relevante fuera el personaje era mayor la posibilidad de que nos
preguntaran por él, así que memorizábamos los nombres con resignación y también
con alegría de cultivar un puntaje seguro. (Zambra, 2011: 58)

Sin embargo, la prueba que configura el Facsímil de Zambra, lo que hace es, justamente, ir en contra de la estandarización y normalización al transformar una única respuesta válida en opciones que se multiplican, al otorgarle al lector la posibilidad de decidir y organizar la(s) historia(s) según sus opiniones, conocimientos o creencias, según su interpretación. El "Facsímil" chileno en el que el temor de ser excluido o de perder un futuro prometedor era manipulado para hacer que el ejecutor de la prueba no intentara hacer nada más allá que aquello para lo que había sido adiestrado se convierte en una parodia que promueve justo lo contrario: la libertad absoluta frente al orden del texto o a lo que se considere correcto en él. El texto espera un lector, convertido en un estudiante ficcional, que, dentro de las limitaciones del formato, tome decisiones.

Con este libro Zambra continúa una exploración sobre las posibilidades de que en la obra artística, en su materialidad, en su formalización, tenga una especial relevancia el concepto a partir del cual se desarrolla. Del concepto que se encuentra detrás de Facsímil se ha intentado dar cuenta en las anteriores páginas, pero el concepto, es decir, la idea que mueve a Zambra a escribir este libro utilizando el formato de la prueba, tiene implícita la relación del lector con la obra y, como se ha señalado anteriormente, con la construcción y orden del texto. Esta idea, la de que el libro puede ser, en definitiva, elaborado por otros, por los lectores, tiene entre otros antecedentes a Duchamp en México (2000), de César Aira, obra en la que el escritor y voz narrativa del texto propone un esquema para que el lector, cada lector futuro o probable, escriba el libro empleando los recibos de compra de un libro sobre Duchamp, o tiene su 
contraparte en el trabajo plástico del artista norteamericano Sol LeWitt, quien nunca llegó a construir ninguna de sus piezas, porque para él la creación consistía en la idea propuesta y no en su ejecución. Al apelar al lector de manera tan directa, Zambra incursiona en una práctica en la que problematiza, también, sobre la propiedad de la obra, sobre el nombre y las restricciones que imponen el nombre autor. Después de que el lector ha resuelto la prueba, e incluso, si no llega a elegir una respuesta específica para cada pregunta, construye una obra específica cuyo esquema solo se limita a seguir el formato que ha propuesto Zambra, pero que es única en sus infinitas posibilidades. Bien se puede suponer que en el mundo en el que se aplicaba la prueba no había dos respuestas iguales. Por tanto, cada prueba respondida era en sí misma la materialización efectiva de una lectura diferente por parte de cada examinando. Pero la lectura de Facsímil es solo un síntoma del mundo de las pruebas escritas que se replica en el resultado de las pruebas. Los exámenes tienen una respuesta correcta. La obra no se evalúa por sus lectores mediante la corrección o incorrección de la lectura. Antes al contrario, es la lectura la que dictamina sobre la corrección o incorrección de unas preguntas y unas respuestas que, en el fondo, se toman como ejemplo de una prueba que revela más a través de su estructura y de su idea de la corrección que lo que revelan las respuestas sobre los estudiantes.

El facsímil, finalmente, se convierte en la ficción paródica de aquello que es la definición del término, 'perfecta imitación de una firma, de un escrito, de un dibujo, de un impreso, etc.' La obra hace una perfecta imitación paródica de un escrito, y al hacerla, mediante un proceso poético de defamiliarización, muestra al lector las posibilidades interminables que aquellas pruebas ocultaban y mostraban simultáneamente. El lector es examinado, sus respuestas, a diferencia de lo que les sucedía a los estudiantes que se enfrentaban con la prueba, no determinará su futuro académico. Pero, en cierta forma, tampoco aquellas pruebas podían permitir conocer cuáles eran, de verdad, las aptitudes académicas de los estudiantes. El autor no ha redactado una novela en la que se diera forma a esta experiencia, ha elegido una experiencia, que bien se ve que no se reduce a un solo país, para mostrar las deficiencias de una comprensión de la lengua que si, ostensiblemente, dice acercar el texto al lector, en la práctica guarda una relación tangencial con la lectura. Y el lector no ha sido informado de una experiencia, se le ha hecho experimentar, sufrir, esa misma experiencia objeto de interés. 


\section{Q Bibliografía}

»Carrión, U. (2016). El arte nuevo de hacer libros. Archivo Carrión I. México: Tumbona.

" Garramuño, F. (2015). Mundos en común. Ensayos sobre la inespecificidad en el arte. Buenos Aires: FCE.

" Gandolfo, P. (2015). "Reseña 'Facsímil de Alejandro Zambra”. Hueders. 13 de abril. Disponible en <http://hueders.cl/pedro-gandolfo-resena-facsimil-dealejandro-zambra/>.

"Soto, A. (2014). "Facsímil (Alejandro Zambra)". Lo que leímos. 1 de diciembre. Disponible en <http://www.loqueleimos.com/2014/12/facsimil-alejandro-zambra/>.

»Vital, A. (2012). Quince hipótesis sobre géneros. México: UNAM / UNAL.

»Zambra, A. (2014). Facsímil. México: Sexto Piso.

"Zambra, A. (2011). Formas de volver a casa. Barcelona: Anagrama. 